Policy and Practice Brief

\title{
Perspectives from the front line: The post-pandemic emergency food system in North Carolina
}

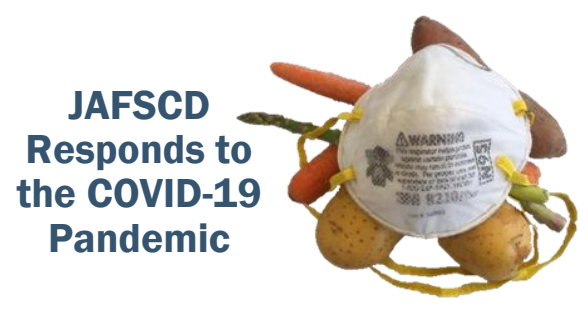

\author{
Amanda S. Hege, ${ }^{\text {* }}$ Nikki McCormick, ${ }^{\mathrm{b}}$ Peggy Robinson, ${ }^{\mathrm{c}}$ \\ Kina M. Charles, ${ }^{\mathrm{d}}$ Jan Jones, ${ }^{\mathrm{e}}$ and Eric Aft ${ }^{\mathrm{f}}$ \\ Second Harvest Food Bank of Northwest North Carolina
}

Submitted November 10, 2020 / Accepted November 11, 2020 / Published online February 11, 2021

Citation: Hege, A. S., McCormick, N., Robinson, P., Charles, K. N., Jones, J., \& Aft, E. (2021). Perspectives from the front line: The post-pandemic emergency food system in North Carolina. Journal of Agriculture, Food Systems, and Community Development, 10(2), 241-245. https://doi.org/10.5304/jafscd.2021.102.018

Copyright (C) 2021 by the Authors. Published by the Lyson Center for Civic Agriculture and Food Systems. Open access under CC-BY license.

\begin{abstract}
The novel coronavirus pandemic has had an immediate effect on food and nutrition security, leading to the most widespread increase in need for food assistance in modern history. At its onset, the pandemic led to emergency food providers experiencing the "perfect storm": surges in demand, declines and changes in types of food donations, limits in the food supply chain, and fewer available volunteers. This policy and practice brief provides perspectives from emergency food providers in North Carolina on their pandemic response along with recommendations for policy and practice applications to promote food security. As the pandemic continues, it is urgent for policymakers, organizations, community

a* Corresponding author: Amanda S. Hege, MPH, RDN, FAND, Nutrition Educator, Second Harvest Food Bank of Northwest North Carolina; 3655 Reed Street; Winston-Salem, NC 27107 USA; +1-336-784-5770; ahege@secondharvest.org

b Nikki McCormick, MSW, MCP, Vice President Partnerships \& Impact, Second Harvest Food Bank of Northwest NC.

c Peggy Robinson, Director Agency Services, Second Harvest Food Bank of Northwest NC.

d Kina M. Charles, MS, RDN, LDN, Director Nutrition Services, Second Harvest Food Bank of Northwest NC.

e Jan Jones, Regional Partnership Manager, Second Harvest Food Bank of Northwest NC.

${ }_{\mathrm{f}}^{\mathrm{E}}$ Eric Aft, Chief Executive Officer, Second Harvest Food Bank of Northwest NC.

\section{Acknowledgments}

The authors thank the partners of Second Harvest Food Bank of Northwest NC for their commitment to providing food and hope to those in need during the onset of the COVID-19 pandemic. This policy and practice brief was informed by conversations with and assessments conducted by staff and volunteers in the emergency food system in North Carolina.
\end{abstract}


members, and other food system stakeholders to encourage collaboration across food system sectors, provide adequate funding for all aspects of distributing healthy foods, promote a continuation of program and policy flexibilities for nutrition programs, and support community-based models that engage a diverse group of organizations and leaders.

\section{Keywords}

Emergency Food, Food Systems, Food Insecurity, Hunger, Food Providers, COVID-19, Pandemic

\section{Overview}

The emergency food system in the United States serves 46.5 million people a year. Feeding America, the largest hunger-relief organization in the U.S., includes a network of 200 food banks and 60,000 food pantries and meal programs. These partner agencies are the mechanism for distributing food directly to individuals and families. Before the COVID-19 crisis began, food insecurity in America was at its lowest point since before the Great Recession, affecting 37 million people nationwide. Since the onset of the pandemic, it is now predicted that more than 54 million people need food assistance (Feeding America, 2020).

As the stay-at-home order was put in place due to the novel coronavirus, emergency food providers experienced the "perfect storm": surges in demand, declines and changes in types of food donations, limits in the food supply chain, and fewer available volunteers. Additionally, the Centers for Disease Control and Prevention (CDC, 2020) issued a statement indicating that individuals and families who access food from food aid, referenced as food-aid seekers, have underlying health conditions that put them at greater risk of contracting COVID-19. The purpose of this policy and practice brief is to provide perspectives from emergency food providers on their pandemic response and recommendations for policy or practice applications to promote food security while keeping communities safe. This brief will address questions related to the capacity of emergency food providers during COVID-19 and how the pandemic has transformed the North Carolina emergency food system.

\section{Scope of the Problem: Impact of COVID-19 on Food and Nutrition Security}

The novel coronavirus has had an immediate effect on the U.S. economy. The unemployment rate rose higher in the first three months of the pandemic than it did in two years of the Great Recession, increasing from 3.8\% in February 2020 to 13.0\% in May 2020 (Kochhar, 2020). As a result, Feeding America Food Banks ("food bank") reported up to a $60 \%$ increase in need for food assistance at distribution sites (Feeding America, 2020). Specifically, Second Harvest Food Bank of Northwest North Carolina, a Feeding America Food Bank that serves 18 counties, conducted a survey with its 460 local food assistance programs that showed approximately $23 \%$ of food-aid seekers from March to May were seeking food assistance for the first time. Additionally, 53\% shared that they were at higher risk for serious illness from the coronavirus, and $63 \%$ responded that it will be "a lot more challenging than usual" to make ends meet (Second Harvest Food Bank of Northwest NC, 2020).

\section{The Response: Adaptations within the Emergency Food System}

In order to continue the mission of nourishing communities while also keeping communities safe, emergency food providers quickly adapted operations, with a focus within three core areas:

\section{Adaptations to the type of food received and distributed:}

With added pressure on grocery stores as schools and restaurants closed, food that may have been donated to a food bank was no longer available. The strain on the larger food supply chain led to 
increased costs, limited availability, and delayed delivery. Emergency food providers experienced a decline in donations of nonperishable goods and triple the amount of produce from farms. The increase in perishable products led to an increase in need for cold storage. There was also an increase in frozen food available through The Emergency Food Assistance Program (TEFAP), a federally supported program, due to suspension of and modifications to international trade.

\section{Adjustments to staff and volunteer capacity:}

Food banks and their network rely on volunteers to supplement staff time. At Second Harvest Food Bank of Northwest NC, on average 900 individuals volunteer monthly, the majority of whom are retired. Second Harvest experienced a 78\% decline in volunteers at the onset of the pandemic. Additionally, to keep everyone safe, it shifted the hours and size of volunteer shifts in order to follow all guidelines set forth by the CDC.

\section{Modifications to operating procedures for food distributions:}

Emergency food providers shifted to supply prepared food boxes through a no-contact drivethrough operation (see Figure 1). Standards of operating procedures (SOP) for food pantry sites provided guidance for preparing food boxes, implementing sanitation protocol, and screening staff and volunteers. Pantries reported that the SOP became their roadmap and helped them feel confident in keeping their doors open.

\section{Changing the Landscape: Innovative Approaches for Food Security}

In response to these changes, the landscape began to change. Food insecurity is one problem at the nexus of a myriad of other inequalities, including income; racial and gender; agriculture and food systems; and access to reliable healthcare and transportation. While navigating COVID-19 and recognizing the nexus of these challenges, the emergency food system in North Carolina developed and enhanced innovations.

\section{Figure 1. An Example of Emergency Food Box Distribution to Food-Aid Seekers}

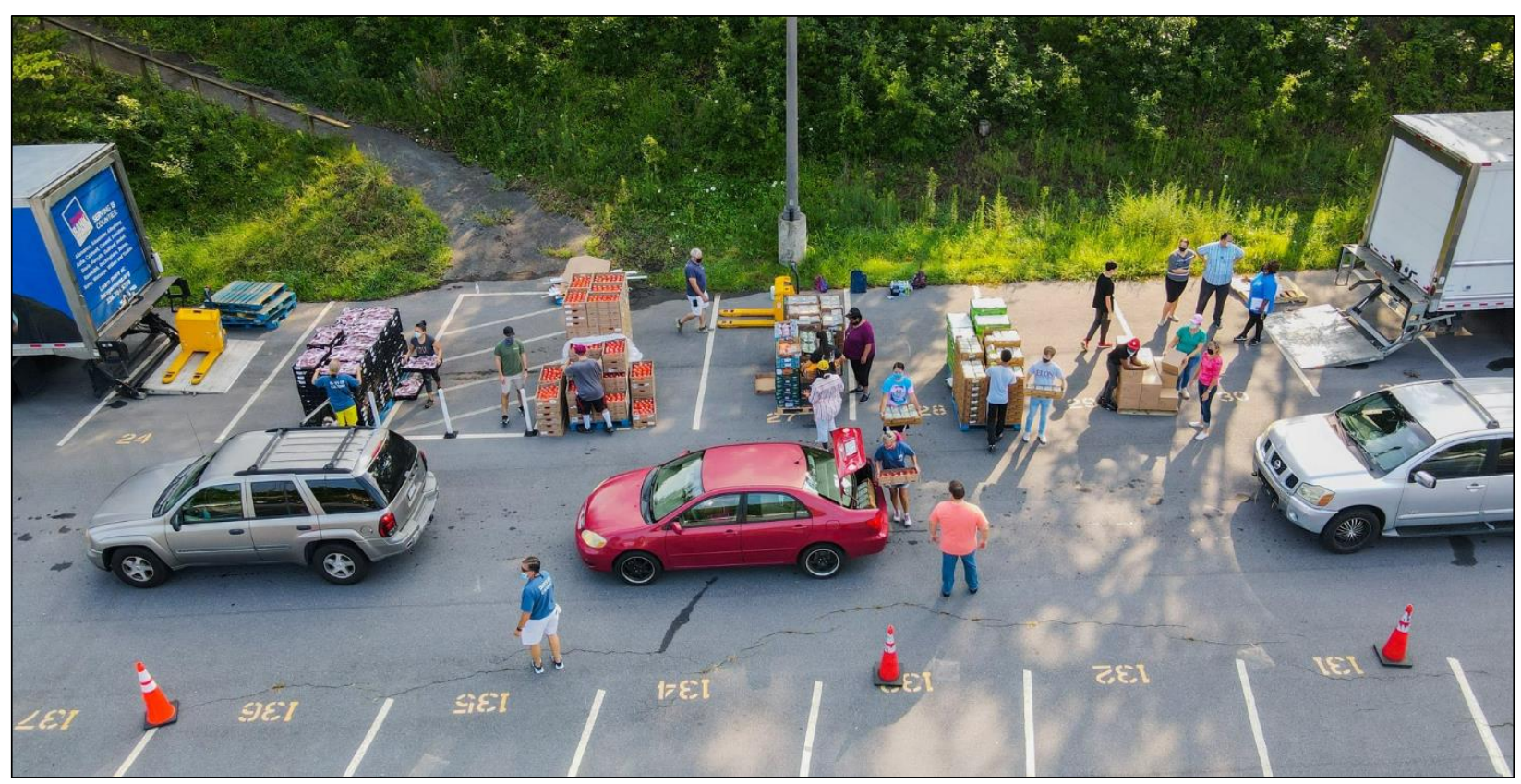


Providers thought creatively about how to bring food directly to the people and how they could fill in for existing food acquisition networks that food-aid seekers had developed but that were no longer viable (e.g., riding to the grocery store with a neighbor). Tractor-trailer loads of emergency food boxes were delivered to families and older adults fearfully sheltering in place. Special mobile pop-up distributions provided fresh produce, dairy, and perishable items. It was common for notes of gratitude to be shared at these pop-up distributions from individuals and families scrambling to stay afloat (see Figure 2).

New partnerships were formed across multiple sectors within the food system. There was an immediate need for a coordination of efforts. Refrigerated tractor trailers that were previously used to deliver food to restaurants were donated for use at food banks to store and distribute perishable products. Direct relationships between local farms and food pantries formed, which offered a market for growers and improved access to healthy food. The National Guard was an essential partner to fill the gap in volunteers.

Expanded opportunities emerged in supporting economic development. Previously established community meal programs that were supplying meals for the Child and Adult Care Food Program (CACFP) or the Summer Food Service Program (SFSP) broadened their reach. For example, one program in northwest North Carolina grew from serving 2,400 meals a week to more than 23,000 meals a week. A collaborative café began providing meals for displaced hospitality workers and artists as well as their families, serving 275 individuals daily.

Local, state, and federal government agencies adapted policies and provided funding appropriations to support COVID-19 responses. For example, the U.S. Department of Agriculture (USDA) worked with state and local partners across nutrition programs to allow states to serve free meals to children, launching the Pandemic-EBT (P-EBT) program, increasing benefits provided by the Supplemental Nutrition Assistance Program (SNAP, formerly known as food stamps), expanding access to online purchasing for SNAP, allowing food substitutions for the Women, Infants, and Children (WIC) 
program, and providing billions of dollars in food through the emergency food system. ${ }^{1}$

Emergency food providers are adapting operations, developing new partnerships, and joining conversations in order to coordinate efforts across a region or state. They are working smarter and harder than ever before; but at this point in the journey, we are left with more questions than answers: How much is enough? And what is the emergency food system's role in meeting the needs of the future?

\section{Policy and Practice Applications: Supporting a Food Secure Future}

Solving hunger and food insecurity requires a multisector approach that engages a diverse group of organizations and leaders. Further action is necessary to ensure access to bealthy food for all. The emergency food providers in North Carolina call on policymakers, organizations, community members, and other food system stakeholders to:

- Encourage collaboration across sectors in the food system in order to effectively and efficiently coordinate efforts and resources;

- Provide adequate funding for all aspects of distributing healthy foods, including the procurement of fresh produce, and support of infrastructure, cold storage, and staffing needs;

- Promote a continuation of new program flexibilities to best serve participants across the 15 nutrition programs within the USDA; and

- Increase initiatives supporting community-based models that engage food-aid seekers and community members in the process of developing and implementing effective strategies.

To meet the rising demand for food assistance, everyone must have a seat at the table. There is still a lot to learn about how to achieve food and nutrition security, but by listening to each other and joining forces, a food secure future is possible.

\section{References}

Centers for Disease Control and Prevention. (2020). Are you at higher risk for severe illness? Retrieved May 20, 2020, from https://www.cdc.gov/2019-ncov/specificgroups/high-risk-complications.html [No longer online]

Feeding America. (2020). The impact of coronavirus on food insecurity. Retrieved August 1, 2020, from https://www.feedingamericaaction.org/the-impact-of-coronavirus-on-food-insecurity/

Kochhar, R. (2020, June 11). Unemployment rose higher in three months of COVID-19 than it did in two years of the Great Recession. Pew Research. Retrieved from https://pewrsr.ch/2UADTTZ

Second Harvest Food Bank of Northwest North Carolina. (2020). COVID-19 client impact survey [Unpublished survey results].

\footnotetext{
1 The full list of COVID-19 flexibilities and adjustments provided by the USDA is available at https://www.fns.usda.gov/coronavirus\#flex
} 